\title{
Study on the Influence of the Operation of Multiple Wind Turbines on the Turbulent Kinetic Energy in the Atmospheric Boundary Layer
}

Fei LI

School of Energy Power and Mechanical

Engineering

North China Electric Power University

Hebei Province, China

lifeihi@163.com

Zheng-ren WU*

School of Energy Power and Mechanical

Engineering

North China Electric Power University

Hebei Province, China

zhengren_wu@163.com

\begin{abstract}
By analyzing the potential influence of the operation of multiple wind turbines on the surface boundary layer was studied. Gambit software was used to establish multiple wind turbine and wind field model, and the Fluent software was used to simulate the flow of four sets of wind turbine in parallel and stagger arrangement. Results show that The turbulence kinetic energy in the near-ground boundary layer is affected by the operation of the wind turbine. The variation rule of the turbulent kinetic energy at different heights and downstream distances is different. Along the vertical direction of the upper part of the wind turbine, The turbulence kinetic energy decreases gradually along the flow direction, and the turbulence kinetic energy of the staggered column arrangement is higher than that of the same row arrangement arrangement as a whole.
\end{abstract}

Keywords-wind turbine; atmosphere boundary layer; turbulence kinetic energy; numerical simulation

\section{Ting-ting LU}

School of Energy Power and Mechanical

Engineering

North China Electric Power University

Hebei Province, China

Lutingting_66@163.com

\section{INTRODUCTION}

With the rapid growth of wind turbines in the world, the influence of wind turbine operation on the near-earth boundary layer (BNL) is attracting more and more attentions. Wind power is a new energy resource with environmental benefits. Turbulent Kinetic Energy (Turbulent Kinetic Energy) is an important variable in micro meteorology, turbulence exchange directly related to the boundary layer of momentum, heat and water vapor transport and redistribution of the energy balance of the atmosphere plays an important role. The turbulence in the trajectory is bound to affect the turbulent kinetic energy in the atmospheric boundary layer due to the turbulent flow of the wind turbine.

Ron Prinn and Chien Wang[1] used the Climate Community Model (CCM3) to simulate the potential climate impacts. Experiments indicate that wind farms increase the near-surface layer momentum drag effect and aggravate turbulence disturbance in the atmosphere. Porté-Agel [2] 
used large eddy simulation to provide a great deal of evidence for the potential impact of wind farms on local meteorology. The results reveal that the Influence of wind farm on meteorology, Wind turbines enhance turbulence disturbances in the vertical direction to enhance mixing of momentum, heat, and humidity in the atmosphere. Mahdi Abkar and Fernando Porté-Agel[3] used LES to investigate the impacts of wind farms on a convective atmospheric boundary layer, The results show that the existence of the wind turbine will affect the increase of the boundary layer by changing the turbulence disturbance in the atmosphere. Wei[4] used the wind tunnel experiment to carry on the corresponding research, The results show that although the variation of surface heat flux in the wind farm area is small, the non-uniform spatial disturbance caused by wind farm layout is very obvious. Stamaria[5] use the theory of rotating blade momentum to point out that the use of wind turbine wind energy, resulting in global atmospheric energy loss.

In this paper, CFD numerical simulation is used to study the turbulence kinetic energy of wind turbines in the boundary layer. Analyzes the influence of wind farm operation on the atmospheric boundary layer, and strives to provide some theoretical basis and reference for the influence of wind farms on the surrounding environment and climate.

\section{TURBULENCE MODEL}

Using the K-W SST two-equation model, the eddy viscosity, k-equation and w-equation as follows[7]:

$$
\begin{gathered}
v_{t}=\frac{a_{1}}{\max \left(a_{1} w ; \Omega F_{2}\right)} \\
\frac{D \rho k}{D t}=\frac{\partial}{\partial x_{j}}\left[\left(\mu+\sigma_{k} \mu_{t}\right) \frac{\partial k}{\partial x_{j}}\right]+\tau_{i j} \frac{\partial \dot{u}_{i}}{\partial x_{j}}-\beta^{*} \rho \omega k \\
\left(\tau_{i j}=-\rho \overline{u_{i}^{\prime} u_{j}^{\prime}}\right)
\end{gathered}
$$$$
\frac{D \rho \omega}{D t}=\frac{\partial}{\partial x_{j}}\left[\left(\mu+\sigma_{w} \mu_{t}\right) \frac{\partial w}{\partial x_{j}}\right]+\frac{\gamma}{v_{t}} \tau_{i j} \frac{\partial u_{i}}{\partial x_{j}}-\beta \rho \omega^{2}+2\left(1-\mathrm{F}_{1}\right) \rho \sigma_{\omega 2} \frac{1}{w} \frac{\partial k}{\partial x_{j}} \frac{\partial u}{\partial x_{j}}
$$

Where the $\Omega$ is Vorticity, $y$ is the distance from the wall.

\section{INFLUENCE OF MULTIPLE WIND TURBINE} OPERATION ON TURBULENT KINETIC ENERGY

A. Area Size

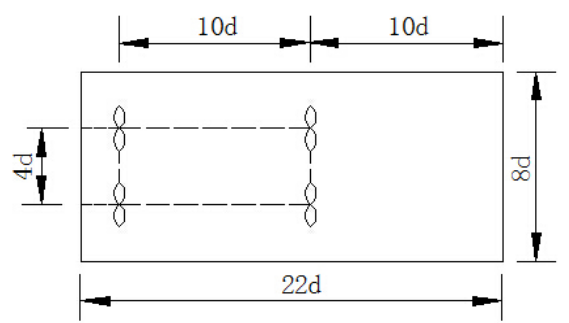

(a) Size of flow field arranged in a row

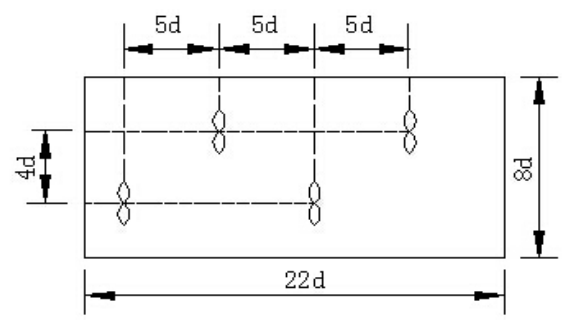

(b) Staggered layout of the flow field size

Figure 1.Size of the whole flow field

\section{B. Comparison of Simulated Results for Turbulent Kinetic} Energy in the Arranged and Staggered Arrangement

Turbine kinetic energy distribution of multiple wind turbines Because the location of the wind turbine layout is quite different, different turbulence kinetic energy patterns at different distances of the wind turbine are not the same.

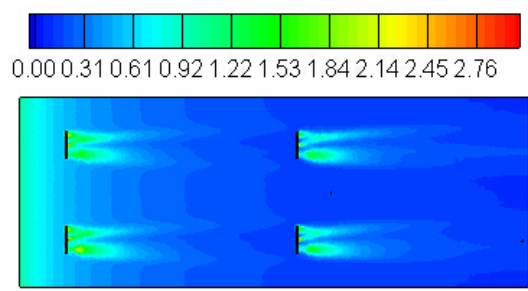

(a)Arranged in a row 


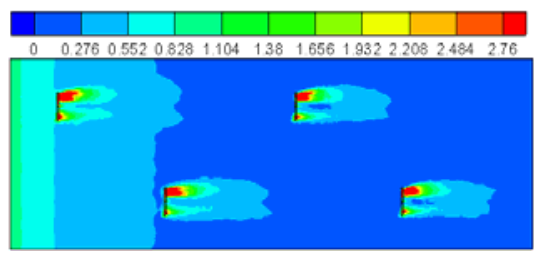

(b)Staggered arrangement

Figure.2 Turbulent kinetic energy of horizontal section at $\mathrm{y}=60 \mathrm{~m}$

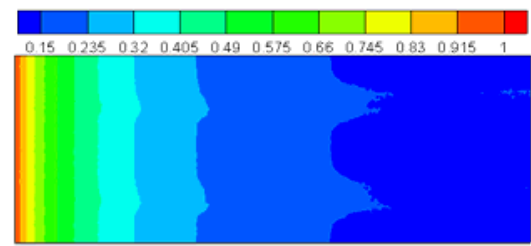

(a)Arranged in a row

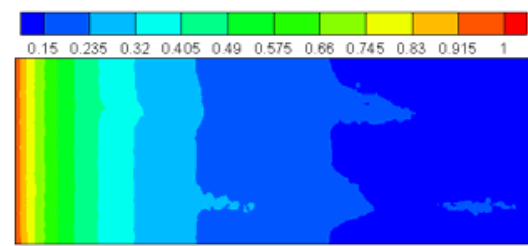

(b)Staggered arrangement

Fig.3 Turbulent kinetic energy of horizontal section at $\mathrm{y}=120 \mathrm{~m}$

Fig. 2 shows the horizontal section of the turbulent kinetic energy at different heights at $60 \mathrm{~m}$, It can be seen from the figure that the turbulent kinetic energy is the largest at the rear of the impeller, whether arranged in series or staggered, and is at the tip of the impeller. And the change of turbulent kinetic energy gradually extends to the far, is still a circular outward diffusion. In the process of diffusion, the fluid with higher turbulent kinetic energy gradually mixes with the fluid with lower turbulent kinetic energy, and gradually decreases. Fig. 3 shows the variation of turbulent kinetic energy at a height of $120 \mathrm{~m}$, It can be seen from the figure there is no change in the trend, but the change in turbulence kinetic energy becomes smaller, and the arrangement of the staggered arrangement than the impact of slightly larger arrangement.

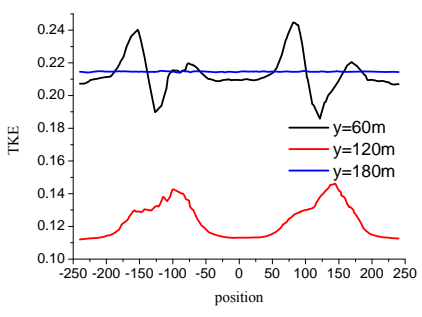

(a) Arranged at the downstream $\mathrm{z}=7 \mathrm{~d}$

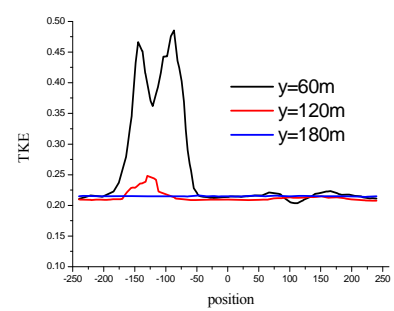

(b) Staggered arrangement downstream $z=7 d$

Figure $4 \mathrm{Z}=7 \mathrm{~d}$ at different arrangement of $\mathrm{x}$-direction turbulence kinetic energy change map

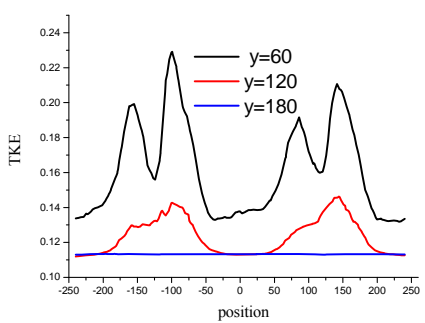

(a) Arranged at the downstream $\mathrm{z}=17 \mathrm{~d}$

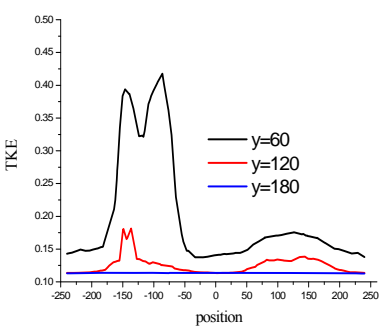

(b) Staggered arrangement downstream $z=17 d$

Figure $5 \mathrm{Z}=17 \mathrm{~d}$ at different arrangement of $\mathrm{x}$-direction turbulence kinetic energy change map 


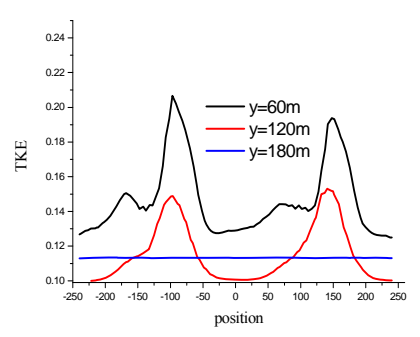

(a) Arranged at the downstream $z=20 \mathrm{~d}$

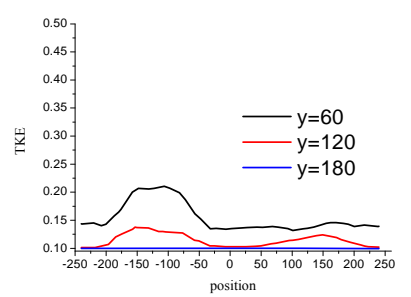

(b) Staggered arrangement downstream $z=20 d$

Figure $6 Z=20 \mathrm{~d}$ at different arrangement of $\mathrm{x}$-direction turbulence kinetic

$$
\text { energy change map }
$$

Figures 4, 5 and 6 show the turbulent kinetic energy distributions in the $\mathrm{x}$ direction at different heights along different downstream locations, It can be seen from the figure that the turbulence kinetic energy tends to decrease gradually with the extension of the downstream wind direction. However, for the local area, the airflow mixing at the tip of the wind turbine is strong and spread to the downstream due to the rotation of the wind wheel. The turbulence kinetic energy distribution of wind turbine is also different from that of the other locations. At the same time, it can be seen from the figure that the disturbances of the staggered arrangement are higher at the same position than the arrangement. Then, as the downstream extends, the higher turbulent energy gradually diffuses into the surroundings and mixes with the surrounding lower turbulent kinetic energy, so that the downstream turbulent energy gradually decreases, but still extends far beyond. From this figure we can see the turbulent kinetic energy generation and dissipation. The disturbance also decreases with increasing height, either in a series arrangement or in a misaligned arrangement, $\mathrm{Y}=180 \mathrm{~m}$ turbulent kinetic energy no longer changes.

\section{Conclusion}

This paper mainly discusses the influence of wind turbine operation on the atmospheric boundary layer, The numerical simulation of the influence of different wind turbines on the boundary layer was carried out by FLUENT. The distribution of turbulent kinetic energy in the boundary layer is analyzed, conclusions as below: The variation rules of turbulent kinetic energy at different heights and downstream distances are different, and the impact of the downstream $17 \mathrm{~d}$ has not been restored, a large impact. At the same time, along the vertical direction of the upper part of the rotor, the change of the turbulent kinetic energy decreases with the increase of the height, and the effect of the stagger arrangement is higher than that of the arrangement, The turbulence kinetic energy decreases gradually along the flow direction, and the turbulence kinetic energy of the whole column is higher than that of the same row arrangement.

\section{ACKNOWLEDGMENT}

The basic scientific research project of the central university(2015MS114)

\section{REFERENCES}

[1] J Hu. "Numerical simulation research on impact of large-scale wind farms on regional climate," Lanzhou University, 2012.

[2] C Wang, R G Prinn. "Potential climatic impacts and reliability of very large-scale wind farms,"Atmospheric Chemistry and Physics, vol.10, 2010, pp. 2053-2061.

[3] F Porteagel, Y T Wu, V Iungo, et al. "Large-eddy simulation of atmospheric boundary layer flow through wind farms". Journal of Wind Engineering \& Industrial Aerodynamics, vol.99, 2011,pp. 154168.

[4] Abkarm, F Porté-Agel. "The effect of free-atmosphere stratification on boundary-layer flow and power output from very large wind farms",Energies, vol. 6, 2013 ,pp, 2338-2361.

[5] W Zhang, C D Markfort, F Portéagel. "Experimental study of the impact of large-scale wind farms on land-atmosphere exchanges"European Geosciences Union. 2013.

[6] M R V S Maria, M Z Jacobson. "Investigating the Effect of Large Wind Farms on Energy in the Atmosphere". Energies, vol. 2, 2009, pp. 816838.

[7] Y Zhou, W Q Qian, Y Q Deng," Introductory analysis of the influence of Menter's k- $\omega$ SST turbulence model's parameters". Acta A erodynamica Sinica ,vol. 28 ,2010, pp.213-217. 